\title{
Optimization of steel structures with one genetic algorithm according to three international building codes
}

\section{Optimización de estructuras de acero con un algoritmo genético y tres códigos de construcción internacionales}

María-Belén Prendes-Gero (Main and Corresponding Author)

Universidad de Oviedo, EPSIG, Department of Construction

Departmental Building 6, 33204, Gijón, Asturias, Spain

mbprendes@uniovi.es

Antonio Bello-García

Universidad de Oviedo, EPSIG, Department of Construction

Departmental Building 6, 33204, Gijón, Asturias, Spain

abello@uniovi.es

Juan-José del Coz-Díaz

Universidad de Oviedo, EPSIG, Department of Construction

Departmental Building 7, 33204, Gijón, Asturias, Spain

juanjo@constru.uniovi.es

Francisco-José Suárez-Domínguez

Universidad de Oviedo, EPSIG, Department of Construction

Departmental Building 7, 33204, Gijón, Asturias, Spain

paco@constru.uniovi.es

\section{Paulino-José García Nieto}

University of Oviedo, Department of Mathematics

Faculty of Sciences, 33007, Oviedo, Asturias, Spain

pauli@constru.uniovi.es

Manuscript Code: 772

Date of Acceptance/Reception: 08.02.2018/17.05.2016

DOI: $10.7764 /$ RDLC.17.1.47

\begin{abstract}
Among all the optimization techniques, the genetic algorithms (GAs) stand out because of their mathematical simplicity, the no necessity of information about the objective function or the constraint functions, and the possibility of working with any type of structure. Although these features suggest an enormous flexibility for working with different building codes, in general, each one is developed for a particular structure and a particular building code. In a world without borders, where one structure can be calculated in one country, manufactured in other and built in a third one, develop one GA for each building code difficult the construction process and increase its cost. In this paper, one GA capable of working with three different building codes (Spanish, European and American) is researched. After analysing the different constraints and stabilities for them, the objective function is defined. Then, and due the influence that the working parameters have in the optimization result, the effect of each parameter over the behaviour of the GA is analysed and a working range for them is established. Finally, the results of the optimization are compared, showing the heaviest structures with the American code and the lightest structures with the European code.
\end{abstract}

Key words: Genetic algorithm; steel structures; minimum weight; ultimate limit states; building code.

Resumen

Los algoritmos genéticos (AGs) se caracterizan por no necesitar un desarrollo matemático complejo, información de la función objetivo o información del tipo de estructura a optimizar. Estas características hacen que sean muy flexibles, aunque, cada vez que la estructura cambia o se emplea un código de edificación diferente, el AG debe ser re-escrito. La globalización ha hecho que una estructura calculada en un país pueda ser construida en otro diferente, siempre que se tenga en cuenta el código de edificación a aplicar, por tanto, es necesario disponer de una herramienta de optimización que se adecúe de una forma rápida a los diferentes códigos, disminuyendo así, el tiempo y coste del proceso. En este trabajo, se desarrolla un AG capaz de trabajar con tres códigos de edificación diferentes (Español, Europeo, Americano). Inicialmente, se analizan las restricciones a aplicar y se definen correctamente las funciones objetivo. A continuación, se estudian los valores de los parámetros que definen el algoritmo para encontrar el rango más adecuado para los tres códigos. Por último, se comparan los resultados de la optimización observando como el código americano es el más conservador con la estructura más pesada y el europeo, el menos, con la estructura más ligera. 
Among all the optimization techniques the GAs are the most popular (Stolpe, 2016). Their great popularity is due to their main features: they are not very complex from a mathematical point of view; they work with fitness and penalties unlike other optimization methods that need information about the objective function or the constraint functions; they can work with any type of structure, but with a fixed structural topology; they allow the use of discrete variables, in this case, the sections from commercial catalogues are assigned to structural beams (Toropov, Mahfouz, \& Westbrook, 1999).

They are based on Darwin theory about species evolution according to which the strongest individuals survive and adapt to new environmental conditions. To carry out the simulation of the evolution rules, simple GAs (Wall, 1996) apply operators of selection, crossover and mutation. Other operators as elitism (Prendes Gero, Bello García, \& del Coz Díaz, 2005; Prendes Gero, García, \& del Coz Díaz, 2006) or rebirth (Galante, 1996; Greiner, Emperador, \& Winter, 2004) are employed with the purpose of improving the behaviour of the GA.

In the field of mixes structures the artificial intelligence has been applied in the calculus of different properties of the materials (Larrúa, Olivera, Caballero, Filiberto, Guerra, Bello, \& Bonilla, 2009), but in steel structures, the optimization has focused on the search for minimum weight structure capable of withstanding a set of external actions. For that, the objective function called modified objective function has two factors: the weight of the structure and the penalty term. The latter, also known as the coefficients weight takes into account the constraints considered in the calculation of the steel structure according to the building code selected. Its purpose is to safeguard the health, safety, and welfare of occupants by regulating construction, building components and materials used. The constraints have been calculated according to the work "Introduction to building codes: a guide to understanding the codes and how they work", published by the National Conference of States on Building Codes and Standards, Inc, in 1999.

Some of the prominent code groups are Eurocodes (AEN/CTN140, 2008), North American codes (American Institute of Steel Construction, 1989, 2005, 1999), and one of many individual country standards as the Spanish building code NBEEA 95 (Ministerio de Fomento, 1996).

Eurocodes were developed in the 1990s by the European Committee for Standardization (CEN), with the idea of standardizing methods to all the member states of the European Union with regard to the calculations and dimensions of structures and prefabricated products. Comparative studies between Eurocode 3 (EC3) (AEN/CTN140, 2008) and NBEEA 95 (Ministerio de Fomento, 1996) for standard steel construction (Serna, Bayo, Castillo, Clemos, \& Loureiro, 1998), show that the two codes apply the concept of ultimate limit state and both of them include failure due to yielding after failure, instability and loss of balance.

Similarly, the American specification for the design of steel buildings, developed by the American Institute of Steel Construction (AISC), has evolved from allowable stress design (ASD) to "Load and Resistance Factor Design" (LRFD) since the first version produced in 1923. This methodology, introduced for the first time in 1986 (American Institute of Steel Construction, 1989, 1999), presents in its 2005 version, a format equivalent to the method of Allowable Stress (American Institute of Steel Construction, 2005).

All optimization processes carried out on steel structures have employed one or another building code (Prendes-Gero \& Drouet, 2011; Numan, 2012; Balea, Hulea, \& Stavroulakis, 2013; Chen \& Rajan, 1999; Degertekin \& Hayalioglu, 2009). However, the similarities between them (Baddoo, 2003; Holmes, Tamura, \& Krishna, 2009) suggest that one genetic algorithm for three building codes could be employed with only a few modifications over the constraints. In a global world where a structure can be calculated in one country, their elements manufactured in other and finally it built in a third one, having such a versatile tool allows to significantly reduce costs and times of the construction process. Besides, the comparison among different building codes allows their improvement and development.

In this paper, three building codes (the Spanish, the European and the American codes) have been analysed and their different constraints have been calculated. Then, for one GA and for each building code, it has written the penalty term of the objective function. After that, for the same steel structure, one combination of working parameters of the GA (probability of mutation $P_{m}$, probability of crossover $P_{c}$, probability of elite $P_{e}$, and size of population $N_{p}$ ) has been defined, with the end of having the optimum behaviour of the elitist GA in the three building codes simultaneously. Finally, the results of the optimization with the three different building codes have been compared and analysed. 
The analysed structure is a three-storey steel building. It is totally symmetric with a separation of 4 meters between storeys and 6 meters between the columns (Figure 1). Three simple load hypotheses have been considered: the weight of the structure itself, a live load due to wind and use, and also a combination of the three, which, in the case of EC3, would correspond to the simplification indicated in that code (AEN/CTN140, 2008).

The structural elements have been divided into four groups of sections, depending on the stress applied and the point of its application, as both factors define the stresses which these elements have to resist. Furthermore, this grouping reduces the computational consumption as it reduces the time of the process, whereas any improvement in the weight of the structure which might be produced by using more groups would be very small (Prendes Gero et al., 2006).

The sections of the structural elements are chosen from a database of 114 different sections. These sections comprised the series IPN, IPE, HEA, HEB and HEM, which belong to the Spanish market but nevertheless are also used in the European market. Although the American code uses different denominations, the above-mentioned series are equivalent to the American forms W, M, S and HP, which can be divided into five groups according to their resistance capacity. Of these five groups, HEB and HEM, according to the American code, are suitable for columns or compression components, as are the series HEA, HEB and HEM. This similarity makes it possible to use the Spanish sections with the American building code, since the error which is committed is very small.

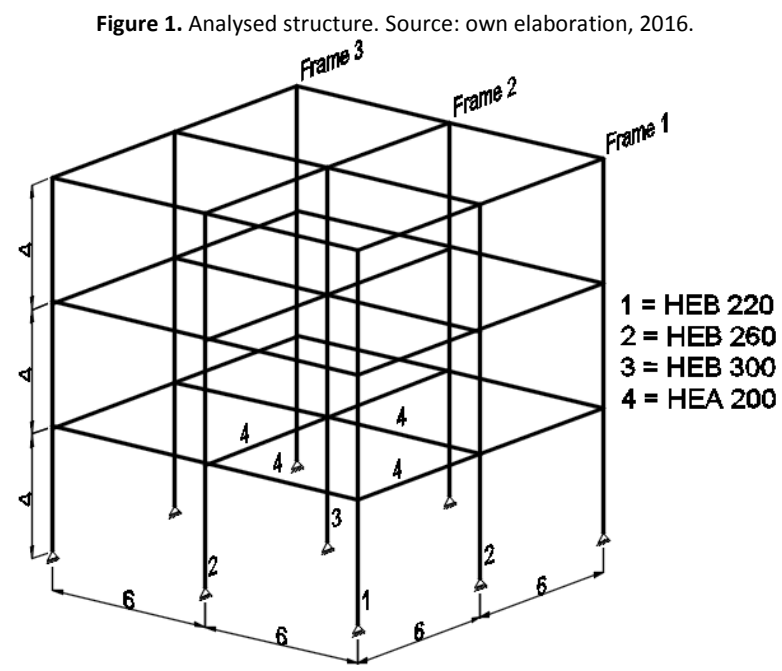

Methodology

In general, the aims of structural optimization, with particular GAs, are to obtain the sections of the structural elements that minimize an objective, subject to certain limits or constraints. These problems are of the restricted optimization type, and for this reason the optimization problems must be transformed into non-restrictive problems. The most appropriate transformation method is to penalize the solutions that violate one or more constraints. On this way, the optimization problem may be expressed mathematically according to (1).

$$
\bar{F}(x, r)=F(x)+\bar{P}(r, G(x), H(x))
$$

where $\bar{F}(x, r)$ is the modified objective function, $F(x)$ is the objective function and $\bar{P}(r, G(x), H(x))$ is the penalty term defined as a function of the penalty coefficient $r$ and the constraint functions $G(x)$ and $H(x)$ (Prendes Gero et al., 2005). More and more the optimization of structures with GAs is driven to get structures with minimum cost, understanding this one like a set of parameters which comprises the transportation, handling, capital, and operating costs (Chau \& Albermani, 2003), (Chau, 2004). However, in our case, the objective is to find the cross-sectional areas of the structural elements that minimize the weight of the structure and that fulfill the constraints established by the applicable building code. Therefore, the first term of the (1) is the weight of the structure in $\mathrm{kg}$, and the second one is the result of multiplying the penalty coefficient $r$ by the constraints in each structural element (2).

$$
\bar{F}(x, r)=F(x)+\sum_{s=1}^{n_{\text {elements }}}\left[r_{1} \cdot G_{s}(x)+r_{2} \cdot H_{s}(x)+\ldots+r_{n_{c}} \cdot T_{s}(x)\right]
$$


Where $n_{c}$ is the number of constraints established by the applicable building code. For calculating the penalty coefficient, the concepts of safe structure and not-oversized structural elements have been considered. A safe structure is the one whose all constraints are equal to or lower than one. In addition, if any constraints values are far below unity the structure is considered oversized. That is to say, there exists another sections with smaller areas that, if assigned to the structural elements, provide constraints closer to unity, thus diminishing the weight of the structure (Prendes Gero et al., 2005, 2006). In this way, the penalty coefficient has an exponential distribution for constraints lower than unity, linear distribution with constraints higher than unity, and one with constraints equal to unity (3).

$$
r(c)=\left\{\begin{array}{ccc}
0 & \text { if } & c=0 \\
e^{2-c} \cdot 10 & \text { if } & 0<c<1 \\
1 & \text { if } & c=1 \\
c \cdot 1000 & \text { if } & c>1
\end{array} \quad c=G_{s}(x)\right.
$$

For calculating the constraints, two types of them have been considered. The first do not depend on the building code and they are the result of dividing the stress of each structural element by the limit stress that the material can resist. The second ones test two of the stabilities included in the building codes (buckling by compression and buckling by compression and bending) and are the result of dividing these stabilities by the limit stress that the material can resist. Both the stresses as the stabilities have been calculated by means of the program Escal3D (del Coz Díaz, Mere, Domínguez, Fdez, Fdez, García, 1998), while the GA is coded in the optimization module (Figure 2) (Prendes-Gero, 2002), both of them were developed by the University of Oviedo.

Figure 2 shows that the optimization process goes on until convergence occurs. In this case the convergence criterion implemented is divided into two classes: the convergence in each evolution ("partial convergence") and the global convergence. In the first case, partial convergence takes place when the best individual of the optimization process has not been modified in the past 10 generations, or when the number of generations has reached the value of 150 . In the second case, global convergence takes place when the best individual of the optimization process has not been modified in a fixed number of rebirths, or the number of generations has reached the value of 300 .

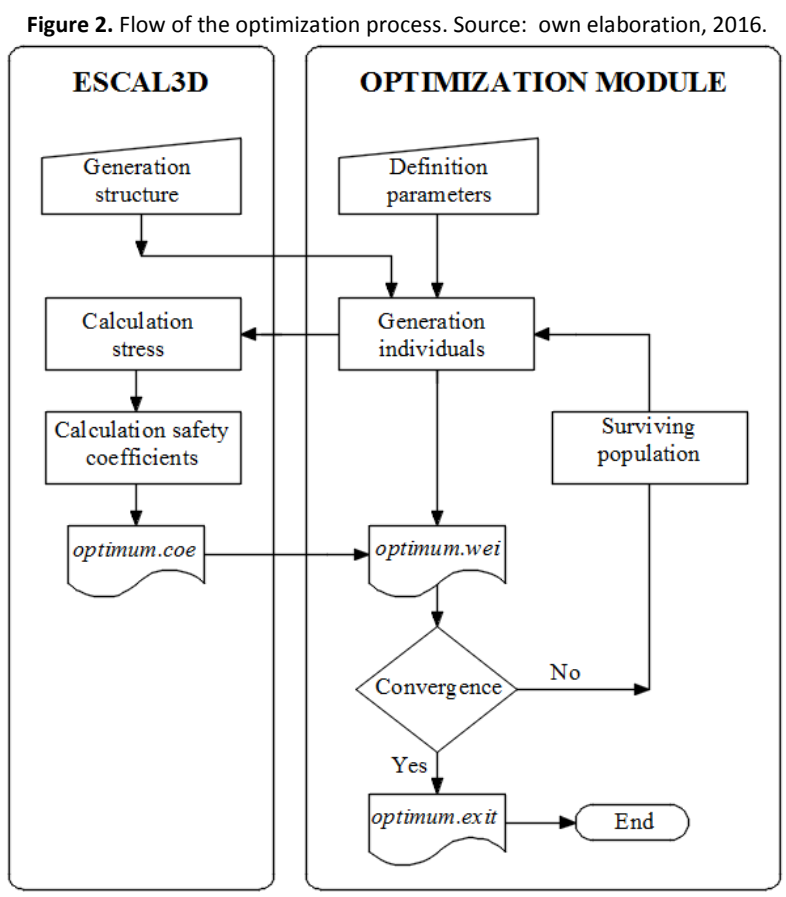

\section{Calculation of stress}

In order to calculate the stress, it is necessary to obtain at several points of the cross-section of each structural element, the axial stress, $\sigma$, the shear stress, $\tau$, and the maximum of the Von Misses stress, $\sigma_{v}(4),(5)$ and (6).

$$
\sigma=\frac{N}{A_{s}}+\frac{1}{D} \cdot\left[M_{y} \cdot\left(-z \cdot I_{z}+y \cdot I_{y z}\right)-M_{z} \cdot\left(y \cdot I_{y}-z \cdot I_{y z}\right)\right]+\frac{B_{t} \cdot \omega_{n}}{I_{\omega}}
$$




$$
\begin{aligned}
& \tau=\frac{1}{D \cdot t} \cdot\left[Q_{y} \cdot\left(-S_{y} \cdot I_{y z}+S_{z} \cdot I_{z}\right)-Q_{z} \cdot\left(S_{z} \cdot I_{y z}-S_{y} \cdot I_{z}\right)-\right]+\frac{M_{x} \cdot W_{t}}{I_{x}} \\
& \sigma_{v}=\sqrt{\sigma^{2}+3 \cdot \tau^{2}}
\end{aligned}
$$

where $N$ is the axial force; $A_{s}$ the area of the cross-section; $D$ the inertia constant; $M_{y}, M_{z}$ the bending moments about the $y$ and $z$ axis respectively; $z, y$ the coordinates of the point where the calculations are made; $I_{x}, I_{y}, I_{z}$ the second moments of area about the $x, y$ and $z$ axes; $l_{y z}$ the product of the inertia of the section; $B_{t}$ the biaxial-moment; $\omega_{n}$ the normalized sectorial coordinate of the cross-section; $l_{\omega}$ the warping constant or warping modulus; $t$ the thickness of the cross-section; $Q_{y}, Q_{z}$ the shear force about the $y$ and $z$ axes; $S_{y}, S_{z}$ the first moments of the area about the $y$ and $z$ axes; $M_{x}$ the torsional moment; $W_{t}$ the torsion modulus, torsion constant or Saint-Venant constant.

\section{Testing for stabilities}

Once it has been checked that the structural elements have been subjected to axial compressive load, the Spanish building code (Table 1) calculates the stresses produced by the buckling by compression and the buckling by compression and bending according to (7) and (13) respectively and, verifies that these values are smaller than the limit of the steel stress $\sigma_{e}$ according to section 3.2.7 and 3.2.9 from (Ministerio de Fomento, 1996).

On the contrary, the European code does not work in terms of stress. For the buckling by compression the European code analyses that its value is not greater than the resistance capacity of the material (8) while, for the buckling by compression and bending verifies that the inequality (14) is satisfied according to section 6.3 from (AEN/CTN140, 2008). In both cases, auxiliary variables have to be calculated (9-10), (15-18).

The American code tests the buckling by compression calculating the allowable stress (11), according to chapter $E$ from (American Institute of Steel Construction, 1989). For the buckling by compression and bending it tests the inequality (19) or (20) according to whether the relationship between the axial compression stress $f_{a}$ and the allowable limit of the axial compressive stress $F_{a}$ is less than 0.15 or not according to chapter $\mathrm{H}$ from (American Institute of Steel Construction, 1989).

Table 1. Testing for stabilities. Source: (AEN/CTN140, 2008; American Institute of Steel Construction, 1989; Ministerio de Fomento, 1996).

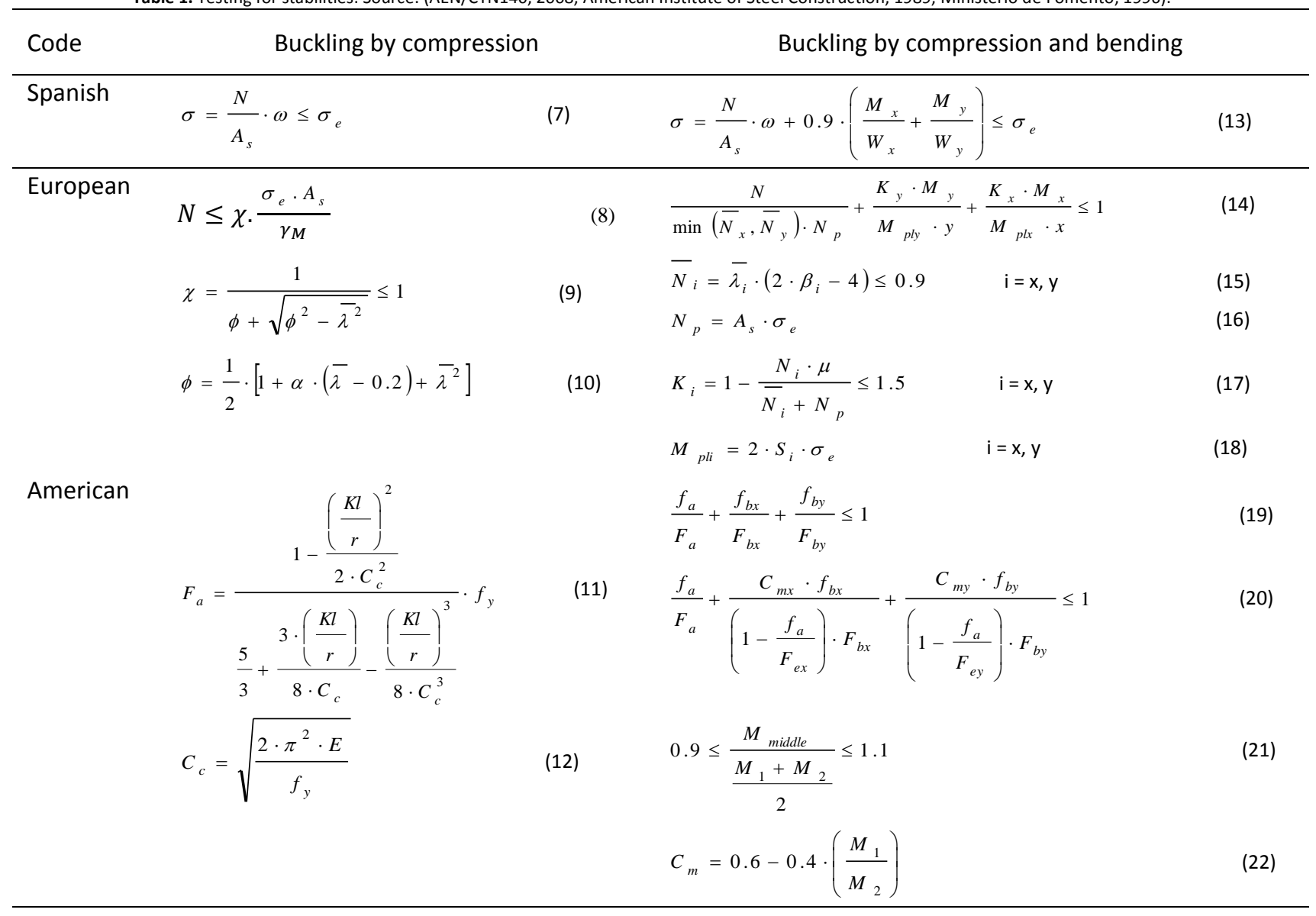


Where:

$\sigma_{e}$ is the limit of the steel stress calculation

$\omega$ is the bending coefficient that depends on the bending length of the structural element $L$, and the smallest radii of gyration $i_{y}, i_{z}$.

$\chi$ is a parameter defined in (9) and function of the non-dimensional slenderness $\bar{\lambda}$ or relationship between the slenderness $(\lambda)$ and the Euler slenderness $\left(\lambda_{E}\right)$, and of the parameter $\phi(10)$.

$\gamma_{M}$ is the partial safety factor for steel defined in EC3

$\alpha$ is the factor of imperfection of each bending curve to which the cross-section of the structural element belongs.

$W_{y}$ and $W_{z}$ are the resistant moduli of the section about $y$ and $z$ axis, respectively

$B_{i}$ is the equivalence factor that depends on the loads.

$\mu$ is an auxiliary term according to the loads.

$f_{b i}$ are the bending moments

$F_{b i}$ are the maximum bending moments.

$F_{e i}$ are function of the slenderness ratio $\left(K L / i_{0}\right)$ and the value of the term $C_{m}$ will be:

- 1 if (21) is fulfilled, in which $M_{1}$ and $M_{2}$ are the moments at the end of the structural element and $M_{\text {middle }}$ is the central moment and moreover, and the coefficient $B$, which determines the bending length of the structural element in each cross-section is greater than or equal to 1.

- 0.85 if $(21)$ is fulfilled and the coefficient $B$ is less than 1.

- $\quad$ Otherwise the value is obtained using (22).

\section{Adjustment of the parameters of the GA for each building code}

In order to adjust the parameters and analyse the impact of this on the algorithm, five complete evolutions of the optimization process are carried out. The domain of each parameter has been set as follows:

- The $N_{p}$ varies from 20 to 200 individuals. It was observed that solutions with a good performance of the implemented GA, with NBE-EA95, were obtained with a value of $N_{p}$ between 60 and 100 individuals. In order to compare the behaviour of the GA with the EC3 and AISC-LRFD codes, the range of variation of $N_{p}$ has been incremented to 200 individuals.

- $\quad$ The $P_{e}$ varies from $0 \%$ to $40 \%$. A greater value of $P_{e}$ produces not only a quicker stagnation of the GA but also bad results in the optimization process.

- The $P_{c}$ varies from $60 \%$ to $100 \%$ (subjected to $P_{c}+P_{e} \leq 100 \%$ ).

- The $P_{\text {mut }}$ varies from $0.1 \%$ to $4 \%$. Since its influence in the results of the process is very low, it usually works with values inferiors to $5 \%$ so that avoid a greater time of computation (Dominguez, Stiharu, \& Sedaghati, 2006), (Kelesoglu, 2007).

In order to be able to carry out all the optimization processes two batteries of computers were used, each with 25 personal computers. However, despite this amount of computational resources, the cost in time was enormous. Populations with 200 individuals needed almost 8000 structure evaluations before reaching a convergence. This means 72 hours of work. In each evaluation and following the selected building code, they are calculated the safety coefficients of the structural elements which make up the optimized structure.

Each complete evolution of the process of optimization generates three text files called "optimum.coe", optimum.wei", and "optimum.exit" (Figure 2). In the first, they are registered the safety coefficients of each individual. In the second the weight of the structure, and in the third all the optimization process, step by step: situation of the current population, that is, whether it is convergent or not; the operators and work parameters; the statistical registers; and, for each individual obtained during the optimization process, the historical values of the safety coefficients of the structural elements.

Given the enormous volume of information handled during the study, a program was developed in PERL which processed the aforementioned text files and extracted the information necessary to carry out the analysis referred to later in this document. In this way, the computer is able to filter information in text files of up to $300 \mathrm{MB}$, automatically and in only a few seconds. 
Once the results have been filtered, the effect that the variation of each parameter has on the behaviour of the GA is analysed. In order to do these both, the variation in the $P_{m u t}, P_{e}$, and $P_{c}$ and the $N_{p}$ are represented for the five evolutions carried out with each combination of parameters against:

- The mean value of the total weight, comprising the weight of the structural elements plus the penalty term.

- The mean value of the weight of the structural elements which make up the structure.

- The mean value of the weight of the safety coefficients.

- The mean value of the number of evaluations of the objective function carried out.

\section{a. Probability of mutation}

The mutation is applied to all the individuals in the new population, with the exception of the individual elite members. The value of bits is changed from 0 to 1 and vice versa in a random way, with the purpose of extending the work space and avoiding premature convergence. The effect of the $P_{m u t}$ on the behaviour of the elitist genetic algorithm is represented in

Figure 3, where the following combination of parameters was used: $N_{p}=20 ; P_{e}=10 \% ; P_{c}=60 \%$.

Figure 3. Effect of the $P_{\text {mut }}$. Source: own elaboration, 2016.
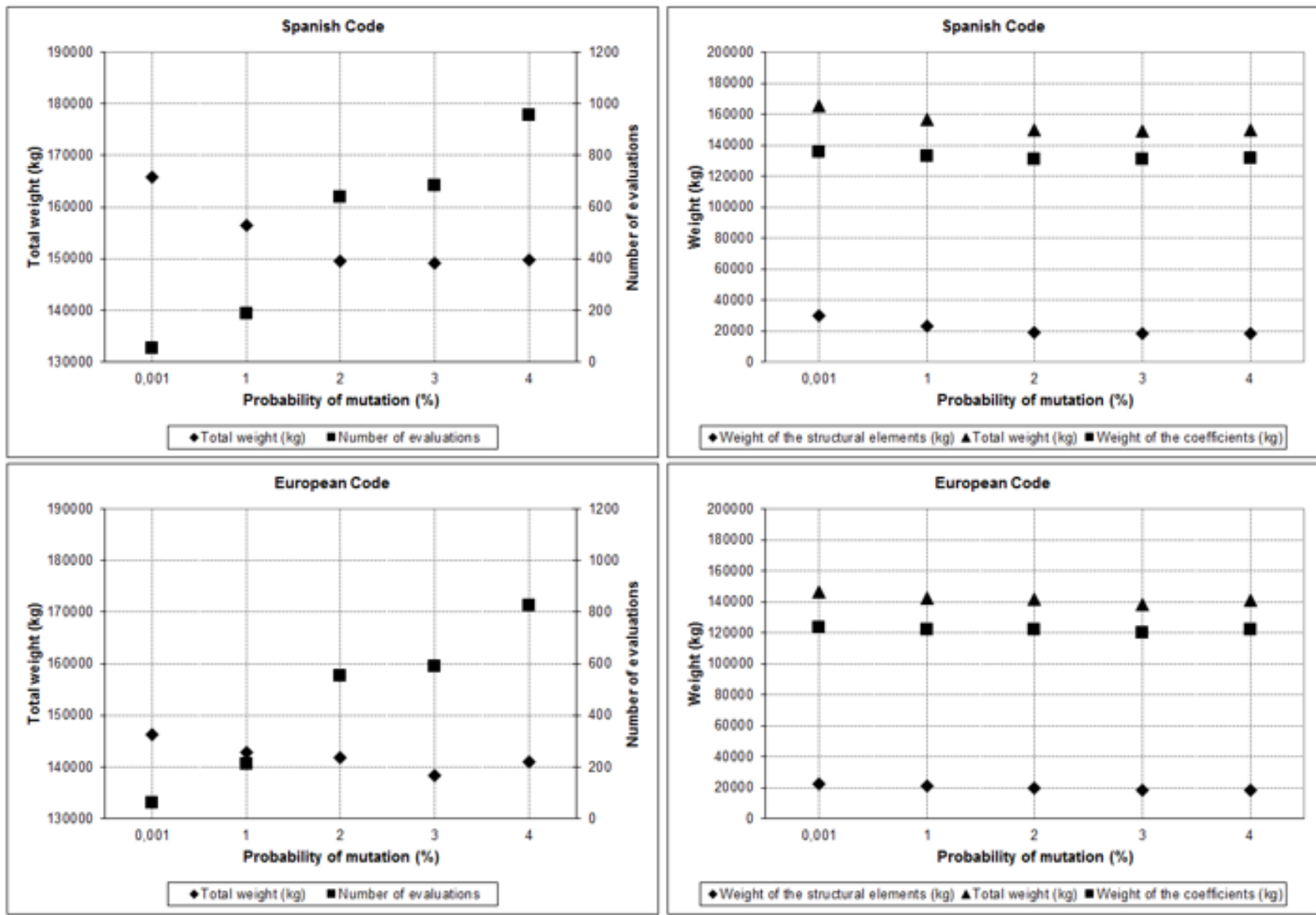

In the graphs, it can be observed that, as the $P_{\text {mut }}$ increases, there is a decrease in the total weight of the structure (sum of the weight of the structural elements in $\mathrm{kg}$ and the weight of the coefficients), until a minimum weight is achieved at probabilities of $3 \%$. As from this value, the weight of the coefficients increases slightly whilst the weight of the structural elements remains practically constant as from mutations of $2 \%$. This behaviour, an increase in the weight of the coefficients, makes the weight of the structure increase, making it possible to establish first working range using $P_{\text {mut }}$ of 2 - 3\%.

Establishing a working range also depends, amongst other factors, on the number of evaluations, and consequently the computational cost, which must be made in order to obtain optimum individuals. Whilst for the European building code, and even for the Spanish one, the number of evaluations hardly varies in $P_{\text {mut }}$ of 2 - 3\%, in the American code the number 
of evaluations goes from scarcely 600 evaluations for $P_{\text {mut }}$ of $2 \%$ to more than 800 for probabilities of $3 \%$. This fact means that within the first established working range it is preferable to work with $P_{\text {mut }}$ of $2 \%$.

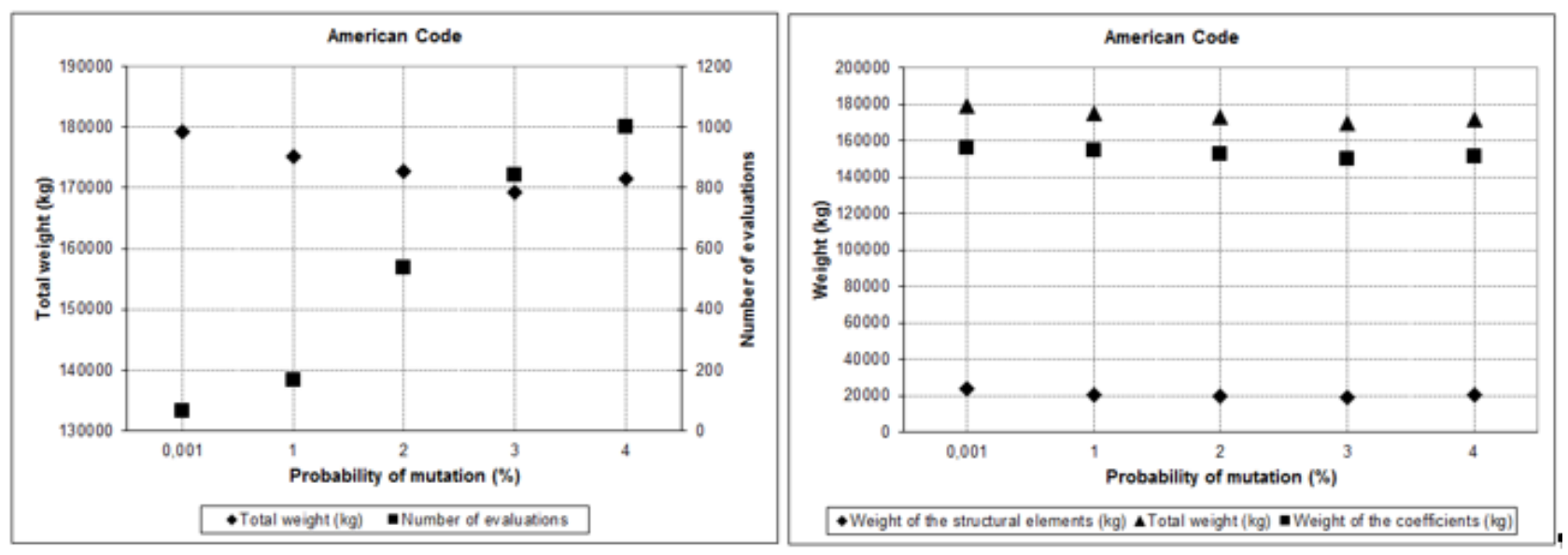

\section{b. Probability of elite}

The effect that the $P_{e}$ has on the elitist GA is analysed and represented for the following combination of parameters: $\mathrm{N}_{\mathrm{p}}$ $=20 ; P_{\text {mut }}=1 \% ; P_{c}=60 \%$. As can be observed in Table 2, an increase in the $P_{e}$ until values of $10 \%$ produces a fast reduction not only in the weight of the structural elements, but also in the total weight. From this point, the weights are still descending, although very slightly, until reaching a $P_{e}$ of $30 \%$ when the weights began to increase.

This behaviour is principally due to the fact that for the same $P_{c}$, the increase in the $P_{e}$ keeps a greater number of individuals from one generation to the next, and there is a decrease in the number of crossovers between individuals. Therefore, a smaller quantity of genetic material is interchanged and the improvement in the descendants is reduced. All of this leads to an increase in the weight of the coefficients, that is, to an increase in the total weight, for a $P_{e}$ greater than $30 \%$. This study makes it possible to establish first working range where the $P_{e}$ is greater than $10 \%$ and smaller than $30 \%$. Furthermore, the number of evaluations decreases as the $P_{e}$ increases. This is logically given that as the $P_{e}$ increases, more genetic material is conserved and this material does not need to be analysed.

\section{c. Probability of crossover}

The phenotype crossover has been employed because it only exchanges the section type assigned to the structural elements, without modifying it previously (Prendes-Gero \& Drouet, 2011; Prendes Gero et al., 2005, 2006). In the three codes, the influence that the $P_{c}$ has over the weight of the structure and over the number of evaluations is very little significant. In this case, the best results are obtained when the sum of the $P_{c}$ and of the $P_{e}$ is next to the $100 \%$, and the $P_{\text {mut }}$ presents values of 2 - $3 \%$.

\section{d. Size of population}

The effect of the $N_{p}$ on the behaviour of the elitist genetic algorithm represented in Figure 4 is analysed using the following combination of parameters: $P_{m u t}=2 \% ; P_{c}=70 \% ; P_{e}=20 \%$. It will be observed that in the three building codes, in populations between 20 and 80 individuals, the mean total weight of the structure descends slightly, although always within a very small range. As from this moment, the value of the mean total weight remains almost constant (with minimum values in populations of 120 individuals), whilst the number of evaluations rises drastically until it reaches values of close to 7800 evaluations in populations of 200 individuals using the European building code.

In order to establish the working range with regard to the $N_{p}$, it is necessary to remember the initial objective of the elitist genetic algorithm: to obtain steel structures which are able to withstand the forces to which they are subjected, whilst weighing as little as possible. Bearing in mind this objective and given that for populations of over 160 individuals the number of evaluations is close to or greater than 5000, the working range is to be found in populations of between 80 and 160 individuals. 
Table 2. Effect of the $P_{e}$. Source: own elaboration, 2016.

\begin{tabular}{|c|c|c|c|c|}
\hline \multirow[b]{2}{*}{$\begin{array}{l}\text { Probability of } \\
\text { elite (\%) }\end{array}$} & \multicolumn{4}{|c|}{ Spanish code } \\
\hline & $\begin{array}{c}\text { Total } \\
\text { weight }\end{array}$ & $\begin{array}{l}\text { Weight of the } \\
\text { structural } \\
\text { elements }(\mathrm{kg})\end{array}$ & $\begin{array}{l}\text { Weight of the } \\
\text { coefficients }\end{array}$ & $\begin{array}{l}\text { Number of } \\
\text { evaluations }\end{array}$ \\
\hline 0 & 158553.628 & 25127.768 & 133425.860 & 304 \\
\hline 10 & 156450.734 & 23288.738 & 133161.996 & 187 \\
\hline 20 & 155746.713 & 22747.244 & 132999.469 & 169 \\
\hline 30 & 152306.575 & 19311.076 & 132995.499 & 155 \\
\hline 40 & 155819.900 & 21989.022 & 133830.878 & 108 \\
\hline \multicolumn{5}{|c|}{ European code } \\
\hline $\begin{array}{l}\text { Probability of } \\
\text { elite (\%) }\end{array}$ & $\begin{array}{c}\text { Total } \\
\text { weight }\end{array}$ & $\begin{array}{l}\text { Weight of the } \\
\text { structural } \\
\text { elements (kg) }\end{array}$ & $\begin{array}{l}\text { Weight of the } \\
\text { coefficients }\end{array}$ & $\begin{array}{l}\text { Number of } \\
\text { evaluations }\end{array}$ \\
\hline 0 & 147471.556 & 24065.728 & 123405.828 & 315 \\
\hline 10 & 144815.900 & 21645.844 & 123170.056 & 258 \\
\hline 20 & 142746.464 & 20861.198 & 121885.266 & 211 \\
\hline 30 & 141377.902 & 19929.888 & 121448.014 & 151 \\
\hline 40 & 144223.894 & 22163.806 & 122060.088 & 101 \\
\hline \multicolumn{5}{|c|}{ American code } \\
\hline $\begin{array}{l}\text { Probability of } \\
\text { elite (\%) }\end{array}$ & $\begin{array}{c}\text { Total } \\
\text { weight }\end{array}$ & $\begin{array}{l}\text { Weight of the } \\
\text { structural } \\
\text { elements }(\mathrm{kg})\end{array}$ & $\begin{array}{l}\text { Weight of the } \\
\text { coefficients }\end{array}$ & $\begin{array}{l}\text { Number of } \\
\text { evaluations }\end{array}$ \\
\hline 0 & 179051.486 & 22377.588 & 156673.898 & 378 \\
\hline 10 & 175226.526 & 20517.200 & 154709.326 & 213 \\
\hline 20 & 175058.390 & 20478.292 & 154580.098 & 166 \\
\hline 30 & 173991.970 & 20116.650 & 153875.320 & 117 \\
\hline 40 & 180838.568 & 23046.790 & 157791.778 & 110 \\
\hline
\end{tabular}

Figure 4. Effect of the $N_{p}$. Source: own elaboration, 2016.

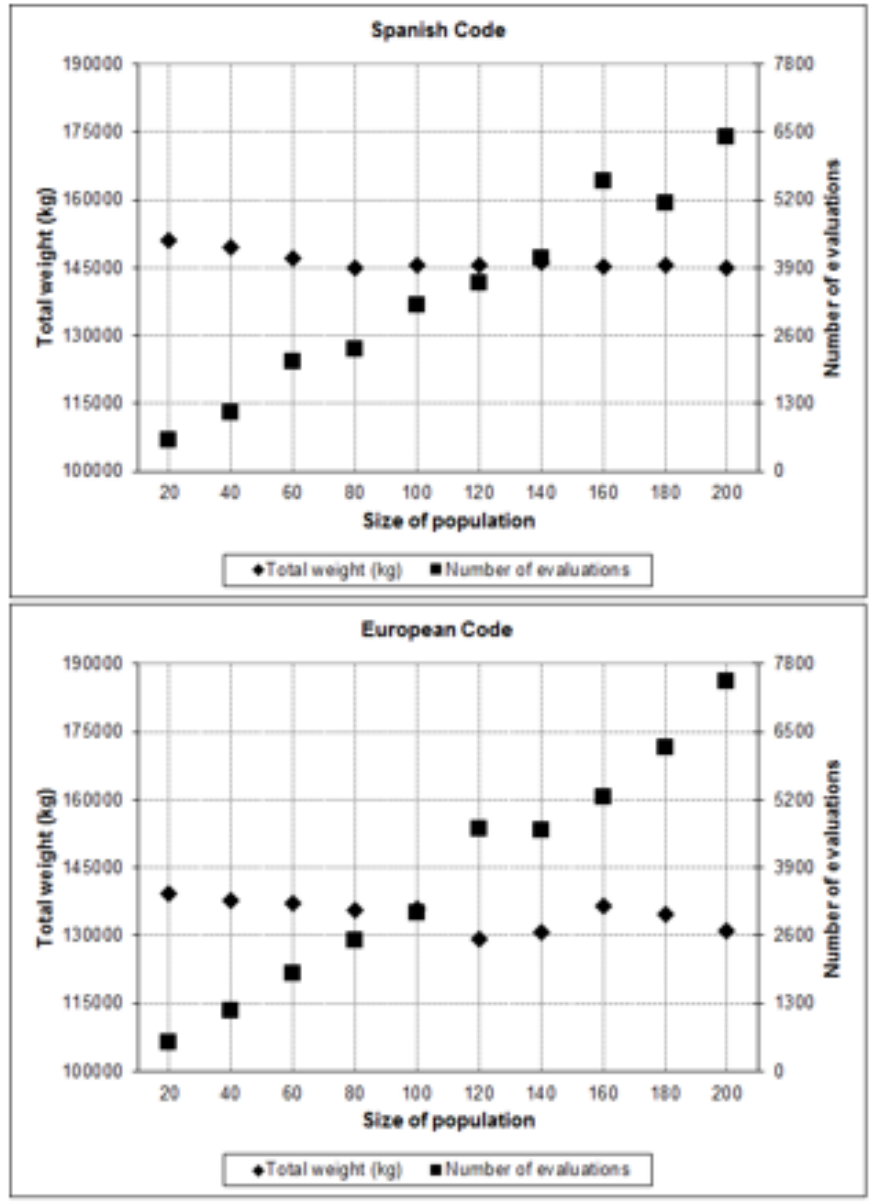




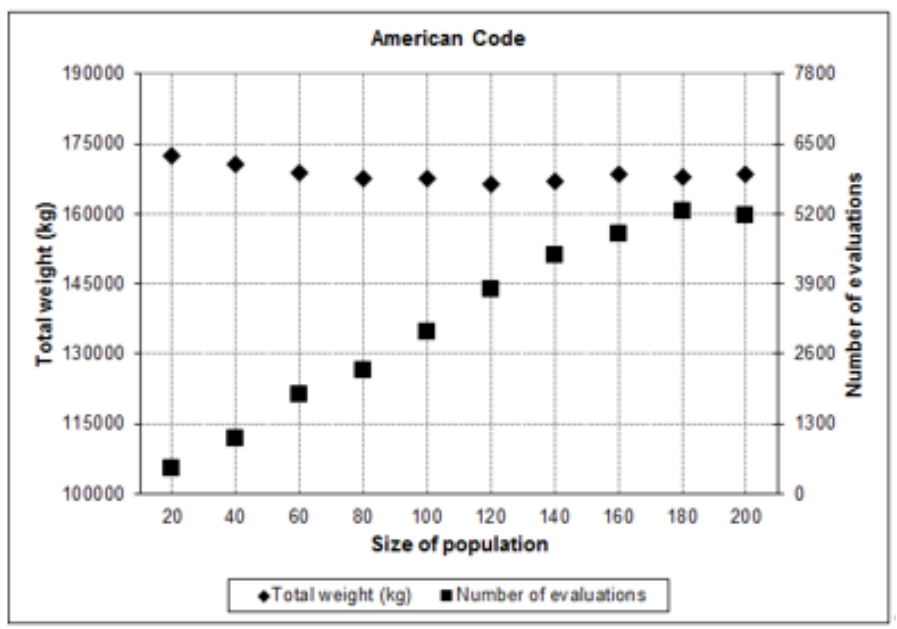

\section{Comparison of the building codes}

In all the parameters analysed, it can be seen that, for each building code, the mean total weight, the weight of the structural elements, and the weight of the coefficients move within a very limited range of values. In all the cases, the values of the mean total weights of the American code are much higher than the values adopted by the Spanish or European building codes. It is the European code which presents the lowest values. In order to analyse this behaviour, the number of evaluations and the mean total weight was represented, using the same combination of parameters as in the study of the size of population: $P_{\text {mut }}=2 \% ; P_{c}=70 \% ; P_{e}=20 \%$ (Figure 5 ).

From Figure 5, it is possible to say that the three building codes have the same computational cost (or the same number of evaluations) when the populations have less than 100 individuals, approximately 6 hours of work. With more individuals the European code presents the major computational cost but the American code the smallest one, reaching 72 hours of work in populations of 200 individuals. Moreover, the mean total weight of the structure shows almost identical behaviour in the three building codes with minimum values appearing in populations of 120 individuals, making it possible to reduce the working range established previously. Furthermore, it can be observed that the values of the final structure obtained with the European building code are always lower than those of the structure obtained with the Spanish and the American codes, and in this case (American code) the structures have the biggest weights.

As has been shown, the mean total weight of the structure has the same distribution as the weight of the coefficients and the weight of the structural elements. For that, the American building code is the one which shows the highest coefficients and consequently the one which produces the heaviest structures together with the shortest time of computation, whilst the European code is the one which produces the lightest structures but with the biggest time of computation. The differences in the results only can be explained saying that the American code is the most conservative one. On the other hand, the Spanish code, always presents intermediate values.

From previous paragraphs, it is appreciated that an increase in the size of populations produces an increase in the time of population. However, the structures obtained are lighter than the structures obtained using conventional software, due fundamentally to the random assignment of sections (Prendes Gero et al., 2006).

In order to compare the results, the best optimum individuals obtained with each building code are analysed. Taking into account that, for a set of parameters that define the genetic algorithm, five complete evolutions of the optimization process were carried out, the three individuals selected are: the third optimum individual in the case of the European building code and to the fifth in the case of the American code, in each case obtained with the combination of parameters $\mathrm{N}_{\mathrm{p}}=120 ; \mathrm{P}_{\text {mut }}=2 \% ; \mathrm{P}_{c}=70 \% ; \mathrm{P}_{\mathrm{e}}=20 \%$. In the case of the Spanish building code, the individual selected was the fifth optimum individual obtained with the combination of parameters $N_{p}=80 ; P_{m u t}=2 \% ; P_{c}=70 \% ; P_{e}=20 \%$. 
Figure 5. Comparison of the building codes. Source: own elaboration, 2016.

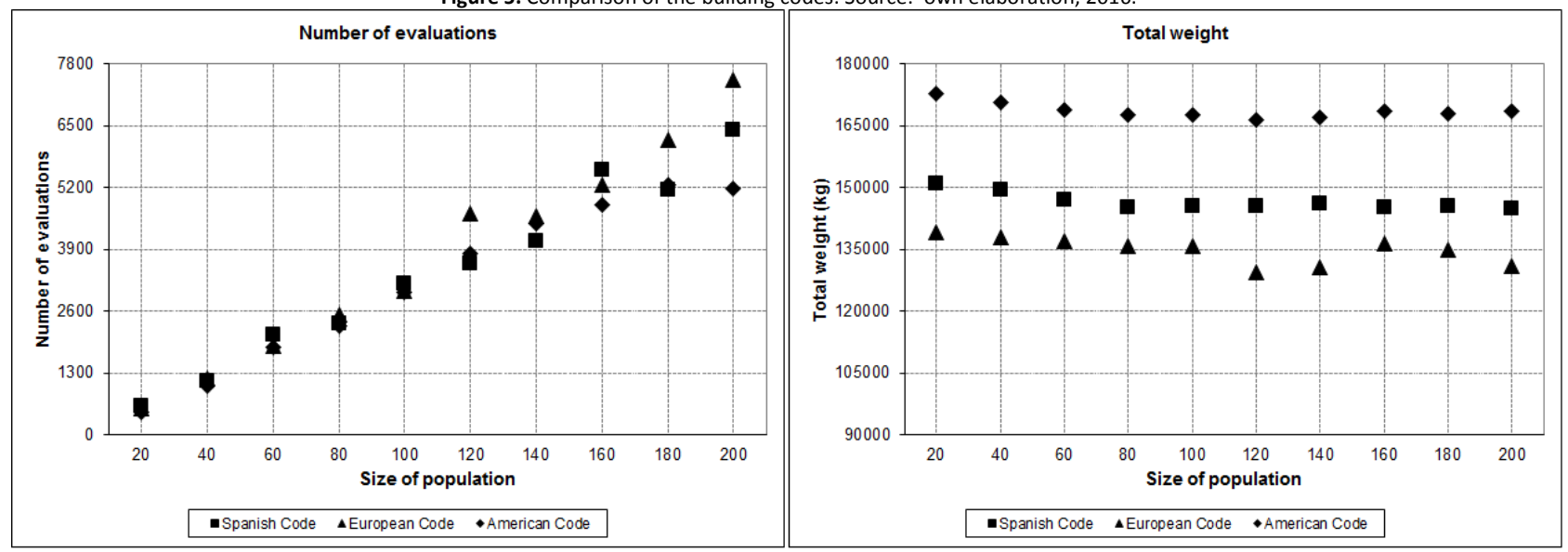

The results reflected in Table 3 again show that the American code is the one which results in the heaviest structure, whilst the European and Spanish building codes produce similar optimum individuals. Furthermore, the study of the three optimum individuals obtained shows that these individuals are repeated on numerous occasions, which would suggest that they are global optimums.

\begin{tabular}{lccc}
\hline \multicolumn{2}{l}{$\begin{array}{l}\text { Table 3. Sections of optimum individuals. Source: own elaboration, } 2016 . \\
\begin{array}{l}\text { structural } \\
\text { elements }\end{array}\end{array}$} & \multicolumn{3}{c}{ Building code } \\
\cline { 2 - 4 } Group I & IPN320 & IPE300 & IPE300 \\
Group II & IPE300 & HEA240 & HEA240 \\
Group III & HEM160 & HEM140 & HEM140 \\
Group IV & IPE330 & IPE330 & IPE330 \\
$\begin{array}{l}\text { Total weight } \\
\text { elements }(\mathrm{kg})\end{array}$ & 16158.3 & 15844.42 & 15844.42 \\
\hline
\end{tabular}

The obtained weight difference is of scarcely $314 \mathrm{~kg}$, that is to say $1.98 \%$ of surplus weight. This is due to the fact that groups of structural elements such as IV have the same cross-section in the three building codes, and that groups such as III have a very similar cross-section in the three building codes. This small percentage difference between weights, despite there being more extra weight in the American structure, makes it possible to affirm that the elitist generic algorithm is suitable for the optimization of steel structures using the three building codes analysed: Spanish, European and American. Figure 6 and Figure 7 reflect the positions of the structural elements obtained in the optimum individuals on the frameworks of the steel building.

Figure 6. Structural elements sections with American Building Code. Source: own elaboration, 2016.

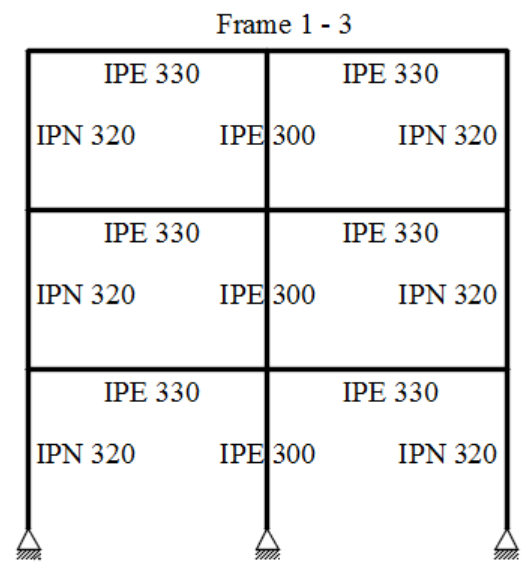

\begin{tabular}{|cc|cc|}
\hline \multicolumn{2}{|c|}{ IPE 330} \\
IPE 300 & HEM & \multicolumn{2}{|c|}{ IPE 330} \\
& & & \\
\hline IPE 330 & & IPE 300 \\
IPE 300 & HEM & 160 & IPE 300 \\
& & & \\
\hline IPE 330 & & IPE 330 \\
IPE 300 & HEM & 160 & IPE 300 \\
& & &
\end{tabular}


Figure 7. Structural elements sections with European and Spanish Building Codes. Source: own elaboration, 2016.

Frame $1-3$

\begin{tabular}{|cr|rr|}
\hline \multicolumn{2}{|c|}{ IPE 330 } & \multicolumn{2}{c|}{ IPE 330 } \\
IPE 300 & HEA & 240 & IPE 300 \\
\hline IPE 330 & \multicolumn{2}{|c|}{ IPE 330 } \\
IPE 300 & HEA & 240 & IPE 300 \\
& & & \\
\hline IPE 330 & IPE 330 \\
IPE 300 & HEA & IPE 300 & \\
& & &
\end{tabular}

Frame 2

\begin{tabular}{|cr|rr|}
\hline \multicolumn{2}{|c|}{ IPE 330 } & \multicolumn{2}{c|}{ IPE 330 } \\
HEA 240 & HEM & 140 & HEA 240 \\
\hline IPE 330 & IPE 330 \\
HEA 240 & HEM & 140 & HEA 240 \\
\hline IPE 330 & & IPE 330 \\
HEA 240 & HEM & HEA 240 & \\
& & &
\end{tabular}

The similarities between the three building codes allow working with a unique genetic algorithm, with no more modifications than the penalty term of the objective function. Specifically, in the stabilities of buckling by compression and buckling by compression and bending.

The analysis of the values of the parameters that define the elitist genetic algorithm $\left(P_{m u t}, P_{c}, P_{e}, N_{p}\right)$ let to establish a working range for the three building codes analysed. This range improves the speed of the optimization process and the weight of the optimum individuals:

- $\quad P_{\text {mut }}$ between $2 \%$ and $3 \%$ although it is recommendable to work with $P_{m u t}$ equal to $2 \%$.

- $\quad P_{e}$ between $10 \%$ and $30 \%$. The value of the $P_{e}$ has to be established together with the value of the $P_{c}$ in such a way that the sum of the two probabilities have to be close to $100 \%$.

- $\quad N_{p}$ between 80 and 100 individuals.

The comparison among the three building codes shows that the American code is the most conservative one, with the heaviest structures, whilst the European code presents the lightest structures.

In a future it would be interesting to extend the study to other building codes and establish one optimized structure that fulfills, at the same time, the different building codes.

AEN/CTN140, T. C. (2008). Eurocode 3: steel structures project. AENOR.

American Institute of Steel Construction. (1989). Specification for Structural Steel Buildings (p. 210). https://doi.org/111

American Institute of Steel Construction. (2005). Specification for Structural Steel Buildings. https://doi.org/111

American Institute of Steel Construction, I. (1999). Manual of Steel Construction, Load and Resistance Factor Design. Chicago, Illinois: American Institute of Steel Construction, Inc.

Baddoo, N. R. (2003). a Comparison of Structural Stainless Steel Design Standards. Building, 131-150.

Balea, I. D., Hulea, R., \& Stavroulakis, G. E. (2013). Implementation of eurocode load cases in optimization problems of steel frames, based on genetic algorithms. Applied Mechanics and Materials, 310(June 2015), 4-6. https://doi.org/10.4028/www.scientific.net/AMM.310.609

Chau, K. (2004). A two-stage dynamic model on allocation of construction facilities with genetic algorithm. Automation in Construction, 13(4), 481490.

Chau, K., \& Albermani, F. (2003). Knowledge-Based System on Optimum Design of Liquid Retaining Structures with Genetic Algorithms. Journal of Structural Engineering, 129(10), 1312-1321.

Chen, S.-Y., \& Rajan, S. D. (1999). Using Genetic Algorithm as An Automatic Structural Design Tool. Proceedings of 3rd World Congress of Structural and Multidisciplinary Optimization, Buffalo, NY., 263-265.

Degertekin, S. O., \& Hayalioglu, M. S. (2009). Optimum design of steel space frames: tabu search vs. simulated annealing and genetic algorithms. International Journal of Engineering and Applied Sciences (IJEAS), 1(2), 34-45. 
del Coz Díaz, J. J., Mere, J. B. O., Domínguez, F. J. S., Fdez, D. F., Fdez, M. A., \& García, A. B. (1998). Aprendizaje interactivo mediante programa de análisis estructural avanzado. Journal of Constructional Steel Research, 46(1-3), 273-274. https://doi.org/http://dx.doi.org/10.1016/S0143974X(98)80029-1

Dominguez, A., Stiharu, I., \& Sedaghati, R. (2006). Practical design optimization of truss structures using the genetic algorithms. Research in Engineering Design, 17(2), 73-84. https://doi.org/10.1007/s00163-006-0020-8

Galante, M. (1996). Genetic Algorithms as an Approach to Optimize Real-World Trusses. International Journal for Numerical Methods in Engineering, 39, 361-382.

Greiner, D., Emperador, J. M., \& Winter, G. (2004). Single and multiobjective frame optimization by evolutionary algorithms and the auto-adaptive rebirth operator. Computer Methods in Applied Mechanics and Engineering (Vol. 193). https://doi.org/10.1016/j.cma.2004.02.001

Holmes, J., Tamura, Y., \& Krishna, P. (2009). Comparison of wind loads calculated by fifteen different codes and standards , for low , medium and highrise buildings. 11th Americas Conference on Wind Engineering, (Awas 08).

Kelesoglu, O. (2007). Fuzzy multiobjective optimization of truss-structures using genetic algorithm. Advances in Engineering Software, 38(10), 717721. https://doi.org/10.1016/j.advengsoft.2007.03.003

Larrúa, R., Olivera, I., Caballero, Y., Filiberto, Y., Guerra, M., Bello, R., \& Bonilla, J. (2009). Aplicación de la Inteligencia Artificial a la Predicción de la Capacidad Resistente Última de las Conexiones en Estructuras Compuestas Acero- Hormigón. Revista de La Construcción, 8(2), $109-119$.

Ministerio de Fomento. (1996). Norma Básica de la Edificación NBE EA-95 : estructuras de acero en edificación. Norma. Madrid, Spain.

Numan, G. (2012). Design and optimization of steel portal frames according to Eurocode using genetic algorithm. Master's Thesis. Chalmers University of Technology, Sweden.

Prendes-Gero, M. B. (2002). Optimization of the design and construction of metallic buildings based on genetic algorithms. Tesis Doctoral. University of Oviedo, Spain.

Prendes-Gero, M. B., \& Drouet, J.-M. (2011). Micro-scale truss optimization using genetic algorithm. Structural and Multidisciplinary Optimization, 43(5), 647-656. https://doi.org/10.1007/s00158-010-0603-x

Prendes Gero, M. B., Bello García, A., \& del Coz Díaz, J. J. (2005). A modified elitist genetic algorithm applied to the design optimization of complex steel structures. Journal of Constructional Steel Research, 61(2), 265-280. https://doi.org/10.1016/j.jcsr.2004.07.007

Prendes Gero, M. B., García, A. B., \& del Coz Díaz, J. J. (2006). Design optimization of 3D steel structures: Genetic algorithms vs. classical techniques. Journal of Constructional Steel Research, 62(12), 1303-1309. https://doi.org/10.1016/j.jcsr.2006.02.005

Serna, M. A., Bayo, E., Castillo, I., Clemos, L., \& Loureiro, A. (1998). Comparative study between Eurocode 3 and NBE-EA-95 for standard steel construction. Journal of Constructional Steel Research, 46(1-3), 140-141. https://doi.org/10.1016/S0143-974X(98)00099-6

Stolpe, M. (2016). Truss optimization with discrete design variables: a critical review. Structural and Multidisciplinary Optimization, 53(2), $349-374$. https://doi.org/10.1007/s00158-015-1333-x

Toropov, V., Mahfouz, S., \& Westbrook, R. (1999). Discrete Design Optimization of 3-Dimensional Steel Structures using a Genetic Algorithm. In 3rd world congress of structural and multidisciplinary optimization, Buffalo, NY, USA, May 17-21, 1999 (p. 7).

Wall, M. B. (1996). A Genetic Algorithm for Resource-Constrained Scheduling by. Design, 62. https://doi.org/10.1007/978-1-60761-842-3_19 